\title{
In tribute to Corwin Hansch, father of QSAR
}

\author{
Yvonne Martin · Terry Stouch
}

Received: 9 June 2011/ Accepted: 15 June 2011/Published online: 28 June 2011

(C) Springer Science+Business Media B.V. 2011

In this issue of Journal of Computer-Aided Molecular Design we pay tribute to Corwin Hansch, who died on May 8 at the age of 91. Professor Hansch (Corwin to almost everyone, at his insistence) was a giant in our field, the 'father' of QSAR, and the vanguard of rational drug design. Thanks to his long-time colleague and coworker, Cynthia Selassie, also of Pomona College, we are, with sadness, publishing his obituary. His picture which graces the cover was kindly provided by Pomona College. Corwin was a friend and mentor to many who went on to advance the field. Consequently, we thought it only fitting to publish the remembrances of at least those few whom we could contact in timely manner.

Corwin's prominence was such that, at its suggestion, Springer Publishing is graciously providing free open access to all JCAMD articles authored or co-authored by him, reference his work, or even mention his name or the now familiar term "Hansch analysis". The articles will stay open access for a period of 3 months.

This issue also contains two Perspectives to pay tribute to Corwin. They complement each other by providing a glimpse of the origins of QSAR and of the relationship between its two inventors, Corwin Hansch and Toshio Fujita. Each has had an illustrious career based on their discovery.

\section{Y. Martin}

Martin Consulting, 2230 Chestnut St, Waukegan, IL 60087,

USA

e-mail: yvonnecmartin@comcast.net

T. Stouch $(\bowtie)$

Science For Solutions, LLC, 6211 Kaitlyn Ct, West Windsor, NJ 08550, USA

e-mail: tstouch@gmail.com
The first Perspective is Hansch's autobiography. It provides stories of his early life, his education, how he came to teach at Pomona College, and of course, QSAR. However, it also contains philosophical musings about the meaning of life and the small part each of us makes in the global scheme of things. This autobiography preserves a valuable record of Corwin Hansch, the person, as well as the scientist. We thank Cynthia Selassie for her effort to edit the original and to make this available to the scientific community.

The second Perspective is a contribution from Toshio Fujita, who as a post-doc with Hansch, was instrumental in the formulation of QSAR. Professor Fujita has been honored with several awards for his research contributions: from the Agricultural Chemical Society in 1967 for promoting research activity and in 1989 for his research performance; and in 1993 the American Chemical Society International Award in Pesticide Chemistry Research. The latter recognized him for his contributions to biological, computational, and synthetic chemistry as applied to agricultural chemicals. Professor Fujita tells the story of how QSAR arose out of the efforts of many laboratories, including their own, to study the structure-activity relationships of plant growth regulators. Although unspoken in either account, QSAR really came to be because both Hansch and Fujita were relentless in their search for the "reason" that some compounds are more potent than other. It is exciting to make these Perspectives available. 